\title{
后慕课时代 SPOC 模式下的《物联网技术与应用》教学改革
}

\section{Teaching Reform of "Internet of Things Technology and Application" Under the SPOC Mode in the Post-MOOC Era}

\author{
薛冷 ${ }^{1}$ 吴昊 ${ }^{1}$ 薛桥 $^{2}$ \\ Leng Xue ${ }^{1}$ Hao $\mathrm{Wu}^{1}$ Qiao Xue ${ }^{2}$ \\ 1. 镇江技师学院 中国·江苏 镇江 $212000 ； 2$. 江苏航空职业技术学院 中国·江苏 镇江 212000 \\ 1. Zhenjiang Technician Institute, Zhenjiang, Jiangsu, 212000, China; \\ 2. Jiangsu Aviation Technical College, Zhenjiang, Jiangsu, 212000, China
}

摘 要: 论文结合 SPOC 教学模式的特点, 从实施以 SPOC 模式为基础的物联网棵程的必要性着手, 对《物联网技术与应 用》课程的教学改革进行研究，旨在转变教师角色，提升学生自主学习能力，从而为最终教学的效果提供保障。

\begin{abstract}
This paper combines the characteristics of the SPOC teaching model, starting from the necessity of implementing the Internet of Things course based on the SPOC model, and studying the teaching reform of the "Internet of Things Technology and Application" course, aiming to change the role of teachers and enhance students' independent learning ability to provide guarantee for the final teaching effect.
\end{abstract}

关键词：后慕课时代; SPOC 模式; 物联网技术与应用; 教学改革

Keywords : post MOOC era; SPOC model; Internet of Things Technology and Application; teaching reform

DOI: $10.36012 /$ sde.v2i11.2346

\section{1 引言}

在当今信息技术和教育工作深度融合的背景下，开放、 共享逐渐成为新时代教育工作的主要趋势, MOOC (慕课) 因具有开放性、共享性以及便捷性的特点得到了广泛的应 用。但是通过具体实践发现, MOOC 的应用还存在着很多 的问题，因此对慕课的发展产生了很大的影响。基于此种情 形, SPOC 教学模式应运而生, 以实现在线教学和课堂教学 的衔接为目的, 促进教学工作的高效进行。

2 实施以 SPOC 模式为基础的物联网课程的 必要性

SPOC 模式的应用不仅可以实现校内外优质教育资源的 共享, 教师的教学模式和理念也有一定的创新。《物联网技术 与应用》课程的实践教学验证该模式在物联网技术应用方面 提供了很大的便利, 可以对学生的实际情况进行全面的分析,
在此基础上提供有针对性的帮助，从某种程度上来说，有效 缓解了学校优质资源和师资欠缺的问题 ; 并且基于 SPOC 模 式创建的《物联网技术与应用》评价体系，促进了学校教学 模式的变革 , 教师教学效率和质量明显提升, 意义重大。

\section{3 以 SPOC 模式为基础的《物联网技术与应}

\section{用》课程教学改革研究}

就 SPOC 模式下的《物联网技术与应用》课程教学改 革工作而言，应将重点放在教学模式改革和课程创新实践培 训研究两大方面。

\section{1 切实做好教学模式改革}

分析《物联网技术与应用》课程内容可以发现，该课 程理论深、专业性强、教学难度大，在这种情况下，如果依 靠传统的课堂教学模式展开教学，不仅教学任务重，教师和 学生都面临巨大压力, 长此以往学生学习兴趣逐渐淡化, 教

【作者简介】薛冷 (1988 ), 男, 江苏徐州人, 计算机网络管理员技师，从事物联网教育教学研究。 
学达不到教学目标 ${ }^{[1]}$ 。因此, 有必要将 SPOC 教学模式利用 起来，充分发挥其教学优势，促使线上自主学习与线下教学 的有效融合，从而为《物联网技术与应用》课程教学的效率 和质量提供保障。

(1)构建信息化教学平台。信息化教学平台是有效促进 和辅助学生完成课前自主学习的重要工具, 在构建平台时应 考虑其科学合理、功能完备、形式丰富等方面的特点。以“嵌 入式系统” 课程为例，信息化教学平台需要在现有“嵌入式 系统” 精品课程网站的基础上, 进一步优化和丰富教学资源。 首先, 在学习任务、任务发布、课后练习及作业评定、课后 评测等功能上需要不断完善, 做好教学过程的互动和监控工 作, 以确保每一教学环节的有效进行 ${ }^{[2]}$ 。其次, 要紧跟物联 网技术中嵌入式系统的快速变化, 对信息化平台的知识拓展 模块进行及时更新，同时也为分层教学的有序进行提供了一 定的保证。最后, 要将微信、QQ 等平台充分利用起来, 建 立课程讨论互动群, 辅助教学目标的达成。在实际教学中, 专业课程群只对本课程相关的师生开放, 以便于师生在课下 进行技术交流，确保教学的整体效果。

(2)教学过程的实施。在《物联网技术与应用》课程的 教学过程中, 应重点关注课前准备、课堂教学以及教学效果 考核评价三个环节, 为了保证最终的教学效果, 教师要将这 三个环节紧密协调起来，相互辅助，形成反馈。

首先, 就课前准备阶段而言, 教师需要充分备课，将 物联网的基本架构剖析清楚并拆分开来, 设计出包括任务目 标、任务要求、任务流程以及任务评价的一整套课前学习任 务单 ${ }^{[3]}$ 。其次, 在课堂教学阶段, 教师应打破传统教学中只 重复基础内容的情况, 在实际教学中需要对学生的课前学习 情况进行全面分析, 以确保教学的有效进行。最后, 在教学 效果的考核评价阶段，应将过程化考核方式的探索重视起 来, 充分利用建立的课程网站以及智能终端平台, 这样不仅 能帮助学生深化相应的知识内容, 也为教师的教学监控工作 提供便利，有利于及时获取教学反馈。

\section{2 加强课程创新实践培训}

要想确保课程创新实践培训的有效进行, 需要做好以 下四个方面的工作：(1)完善培训内容，利用 $\mathrm{MOOC}$ 平台发 布学习内容。创新实践培训内容应包括物联网技术知识体系 以及物联网基础架构、硬件设备配置和安装、软件调试、故
障处理、系统维护等物联网竞赛技能培训内容。(2)丰富共享 的网上教学资源。教师要积极探索通过慕课平台提供课程学 习的课件、微课视频等，从而更加有效地帮助学生完成课前 的预习, 为后续教学的高效进行奠定基础。(3)跟踪、分析学 生的培训记录。在实际教学中, 利用 $\mathrm{MOOC}$ 平台对学生的 各项学习数据和信息进行记录，并对其创新实践培训过程中 遇到的问题进行跟踪分析，从而实现精准指导和解决问题。 (4)提供在线实验环境。教师还可以将 $\mathrm{MOOC}$ 平台中的 $\mathrm{Web}$ 接口充分利用起来，以此引导学生通过 Web 接口访问物联 网实验平台, 这就为学生提供了在线实验的机会, 真正实现 了高效的在线教学。

\section{4 《物联网技术与应用》MOOC 课程平台的} 构建

《物联网技术与应用》MOOC 课程平台包括基本界面、 互动板块以及后台管理三大模块 其中 基本界面包括对《物 联网技术与应用》课程中相关信息的简单介绍，让学生可以 更快地熟悉课程 ; 互动板块是 $\mathrm{MOOC}$ 课程平台建设的关键 和重点，其中主要包括在线授课、在线考勤、线上作业、线 上考试等模块; 而后台管理板块是平台的次重点，主要有学 生信息管理、相关试题管理、教师权限管理以及留言信息管 理等内容。

\section{5 结语}

总而言之, SPOC 教学模式在《物联网技术与应用》 $\mathrm{MOOC}$ 课程平台中的应用，将信息技术和课堂教学有效融 合起来，对于一些专业性强、信息量大以及难度高的课程， 也可以很好地开展在线教学，不仅为最终的教学效果提供了 保障，学生的自主学习能力也得到明显提升，教师角色发生 转变, 与新时代教育发展形势相符。

\section{参考文献}

[1] 刘陶. 基于 SPOC 的高校实践课程教学改革与探索 [J]. 计算机 教育 ,2020(6): 184-189.

[2] 王莉, 季洁, 李超良.“后慕课时代”SPOC 模式下《物联 网技术与应用》教学改革研究与实践 [J]. 电脑知识与技 术 ,2019,15(19):128-129.

[3] 李海波. 基于 SPOC 教学模式的高职课程改革研究 [J]. 教育现 代化 ,2019,6(25):49-50. 